\title{
Cellular Physiolosy

\section{Identification of Small Signalling Molecules Promoting Cardiac-Specific Differentiation of Mouse Embryonic Stem Cells}

\author{
Agapios Sachinidis $^{1^{*}}$, Silke Schwengberg ${ }^{2 *}$, Rita Hippler-Altenburg ${ }^{1}$, \\ Devi Mariappan ${ }^{1}$, Naidu Kamisetti ${ }^{1}$, Bianca Seelig ${ }^{3}$, Albrecht \\ Berkessel $^{3}$ and Jürgen Hescheler ${ }^{1}$
}

${ }^{1}$ Centre of Physiology and Pathophysiology, Institute of Neurophysiology, Cologne, ${ }^{2}$ Axiogenesis AG, Cologne, ${ }^{3}$ Institut für Organische Chemie der Universität zu Köln, *These authors contributed equally to this work

\section{Key Words}

Embryonic - Stem - Cells - Cardiomyogenesis • Signalling $\cdot$ Molecules $•$ Verapamil $\cdot$ Cyclosporin

\begin{abstract}
Identification of signalling cascades involved in cardiomyogenesis is crucial for optimising the generation of cardiomyocytes from embryonic stem cells (ES cells) in vitro. We used a transgenic ES cell lineage expressing enhanced green fluorescent protein (EGFP) under the control of the $\alpha$-myosin heavy chain $(\alpha-M H C)$ promoter (paMHC-EGFP) to investigate the effects of 33 small molecules interfering with several signalling cascades on cardiomyogenesis. Interestingly, the L-Type $\mathrm{Ca}^{2+}$ channel blocker Verapamil as well as Cyclosporin, an inhibitor of the protein phosphatase $2 \mathrm{~B}$, exerted the most striking pro-cardiomyogenic effect. Forskolin (adenylate cyclase stimulator) exerted the most striking anti-cardiomyogenic effect. The cardiomyogenic effect of Cyclosporin and Verapamil correlated with an expression of early cardiac markers
\end{abstract}

\section{KARGER}

Fax +4161306 1234

E-Mail karger@karger.ch

www.karger.com
(C) 2006 S. Karger AG, Basel

1015-8987/06/0186-0303\$23.50/0

Accessible online at:

www.karger.com/journals/net
Nkx2.5 and GATA4.Compared to the effects on late developmental stage embryoid bodies (EBs) stimulation of early developmental stage EBs (1-day old) with Verapamil or Cyclosporin for $48 \mathrm{~h}$ resulted in a potent cardiomyogenic effect. Accordingly, enhanced expression of $\alpha-M H C$ mRNA and EGFP mRNA was observed after stimulation of the early developmental stage EBs for $48 \mathrm{~h}$. No expression of $\alpha$-smooth muscle actin or platelet endothelial cell adhesion molecule-1 (PECM-1) as well as of neuronal genes (Nestin, Neurofilament $\mathrm{H}$ ) has been observed demonstrating a preferentially pro-cardiomyogenic effect by both molecules.

Copyright (C) 2006 S. Karger AG, Basel

\section{Introduction}

Embryonic stem cells (ES cells) isolated from the inner cell mass of early blastocyst-stage embryos are pluripotent [1], possessing the unique property to

Agapios Sachinidis

Centre of Physiology and Pathophysiology

Institute of Neurophysiology

Robert-Koch-Str. 39, 50931 Cologne (Germany)

E-Mail a.sachinidis@uni-koeln.de 
differentiate in vitro into any somatic cell type, including cardiomyocytes, haematopoietic progenitors, skeletal myocytes, smooth muscle cells, adipocytes, chondrocytes, endothelial cells, neurons and glia, and pancreatic islet cells [2]. When cultured in the presence of leukaemia inhibitory factor (LIF), murine ES cells remain undifferentiated and can be propagated indefinitely [1, 3]. Upon withdrawal of LIF, ES cells spontaneously and irreversibly differentiate into multicellular aggregates, socalled embryoid bodies (EBs). These aggregates resemble early post-implantation embryos and contain derivatives of all three germ layers (for review see [4]). ES cells may offer an unlimited source of diverse somatic cells for potential clinical applications of various degenerative disorders such as myocardial infarction, Parkinson's disease, diabetes and hepatitis. Additionally, ES cellderived cell types and tissues can be used to establish cell-based in vitro test systems for drug screening, toxicity testing, and functional analysis.

Applying appropriate culture conditions allows generation of cardiomyocytes from ES cells in vitro. The process of cardiomyogenesis involves differentiation, proliferation, and migration of early cardiomyocytes. Identifying soluble factors and signal cascades involved in cardiomyogenesis is crucial for optimising the generation of cardiomyocytes in vitro and understanding cardiac development in vivo.

In this context, experimental models are required allowing rapid and "easy-to-handle" parallel testing of small molecules which may influence the differentiation of ES cells towards cardiomyocytes. For this aim we used a transgenic ES cell lineage expressing enhanced green fluorescent protein (EGFP) under the control of $\alpha$-myosin heavy chain $(\alpha-\mathrm{MHC})$ promoter (p $\alpha \mathrm{MHC}-\mathrm{EGFP})$, allowing us to investigate 33 small molecules (see table 1) interfering with various cellular signalling cascades on cardiomyogenesis in ES cells. As shown by Kolossov et al. [5], expression of EGFP in the cell line used correlated with appearance of other cardiac markers, and can therefore be used to quantify the amount of cardiac cells within the differentiated EB.

\section{Materials and Methods}

\section{Materials}

Except Serotonin, TTX, Ganglioside GM1 and Testosteron that have been obtained from Sigma-Aldrich Chemie GmbH (Schnelldorf, Germany), all other substances were purchased from Merck Biosciences Ltd (Beeston/Nottingham, UK) (see Table 1).

\section{Cell Culture and Experimental Design}

Mouse ES cells (D3, ATCC CRL 1934) were stably transfected with the paMHC-EGFP construct containing the gene of the EGFP under control of the $\alpha$-MHC promoter as previously described [5]. To start differentiation, ES cells were trypsinised and cultured in $6 \mathrm{~cm}$ Petri-dishes (Greiner, Darmstadt, Germany) in suspension $\left(2 \times 10^{6} \mathrm{cells} / \mathrm{ml}\right)$ on a rocking table (GFL 3006, GFL, Braunschweig, Germany) in Iscove's modified Dulbecco's Medium (IMDM) with $20 \%$ FCS, nonessential amino acids $(0.1 \mathrm{mM})$ and $\beta$-mercaptoethanol $(0.1$ $\mathrm{mM}$ ) (Invitrogen, Karlsruhe, Germany) at $37^{\circ} \mathrm{C}, 5 \% \mathrm{CO}_{2}, 95 \%$ humidity for $24 \mathrm{~h}$ to form EBs. About fifty EBs were transferred to each well of bacterial 6 well plates (Greiner, Darmstadt, Germany) and test compounds were added at the concentrations indicated in the figures. Each compound concentration was tested in triplicates in three individual experiments. On day five, half of the medium was replaced by fresh medium and fresh test compounds were added. EBs were monitored during the differentiation process using a fluorescent microscope (Axiovert $100 \mathrm{M}$, Zeiss, Jena, Germany) with a FITC filter set (AF Analysentechnik, Stuttgart, Germany) and x10 or x20 objectives. On day 14, EBs of each well were counted, washed twice in $5 \mathrm{ml}$ PBS (Invitrogen), lysed in lysis buffer (20mM Tris$\mathrm{HCl} / 0.5 \%$ Triton $\mathrm{X} 100$ ) and fluorescence in the lysates was measured using a Tecan Safire ${ }^{\circledR}$ (Tecan, Crailsheim, Germany) at an excitation wavelength of $476 \mathrm{~nm}$ and an emission wavelength of $508 \mathrm{~nm}$ (Fig. 1). Addtionally, protein content in lysates was measured using a standard Bradford ${ }^{\mathrm{TM}}$ Protein Assay (Coomassie Plus Reagent, Pierce, Rockford, IL) and a BSA protein standard (Sigma-Aldrich, Taufkirche, Germany). Fluorescence values were normalized either to $1 \mathrm{~EB}$ or to protein content $(\mu \mathrm{g} / \mathrm{ml})$ and expressed as percent of control values (vehicle only). Both, a significant decrease and a significant increase of values, compared to vehicle controls, represent an effect on cardiomyogenesis. To determine an $\mathrm{EC}_{50}$ for Verapamil and Cyclosporin, 5 concentrations ranging from $1 \mathrm{nM}$ to 10 $\mu \mathrm{M}$ were used. The obtained values were linearly interpolated between adjacent points, and the first concentration - starting from the lowest - to exceed an effect of $50 \%$ was determined as the $\mathrm{EC}_{50}$. Alternatively, on day 7, single EBs were plated in each well of 24 well tissue culture plates (Becton Dickinson, Heidelberg, Germany) and medium and compounds were added as described above. Photomicrographs of representative EBs were taken on day 14 using the Zeiss Axiovert with a FITC filter set. Representative expression of EGFP in ES cell derived cardiac cells treated with $10 \mu \mathrm{M}$ Verapamil is shown in Fig. 1.

To determine the time point of differentiation at which Verapamil and Cyclosporin A promote cardiomyogenesis, a time-staggered protocol was established as indicated in Fig. 5. Briefly, compounds were added to EBs either in suspension or plated on 24 well plates as described above at 4 different time points (day 1, 3, 5, and 7) for $48 \mathrm{~h}$. After incubation with the compounds, EBs were washed twice with differentiation medium and were further cultured in differentiation medium without compounds until quantification of cardiomyocytes on day 14 . To clarify if inhibition of cardiomyocyte development seen by some compounds is due to a pure cytotoxic effect, the standard cytotoxicity test, the sodium 3'-[1-phenyl-aminocarbonyl)-3,4-

Sachinidis/Schwengberg/Hippler-Altenburg/Mariappan/Kamisetti/ Seelig/Berkessel/Hescheler 
Table 1. Overview about the small molecules promoting and inhibiting cardiomyogenesis. The order of the potency has been set according to the results from Figure 2. Activator: Stimulatory effect $>50 \%$; Weak activator: Stimulatory effect $<50 \%$. Inhibitor: Inhibitory effect $>25 \%$; Weak inhibitor: Inhibitory effect $<25 \%$.

\begin{tabular}{|c|c|c|}
\hline Small molecule & Action Mechanism & $\begin{array}{c}\text { Effect on } \\
\text { Cardiomyoge } \\
\text { nesis }\end{array}$ \\
\hline \multicolumn{3}{|c|}{$\mathrm{Ca}^{2+}$ and $\mathrm{pH}$ Signalling } \\
\hline Ryanodine & Inhibition or an activation of the $\mathrm{Ca}^{2+}$ release of from SR [9] & Activator \\
\hline Thapsigargin & Selective inhibitor of SERCA [13] & No effect \\
\hline Caffeine & Releases from $\mathrm{Ca}^{2+}$ from SR [12] & No effect \\
\hline $\begin{array}{l}\text { Methoxyverapamil, } \\
\mathrm{HCl}\end{array}$ & Antagonist of the plasma membrane L-type $\mathrm{Ca}^{2+}$ channels [10] & Activator \\
\hline Bay K8644 & L-type $\mathrm{Ca}^{2+}$ channel agonist [11] & No effect \\
\hline \multicolumn{3}{|c|}{ Protein Phosphorylation } \\
\hline Genistein & Inhibitor of tyrosine kinases [15] & Inhibitor \\
\hline PD 98059 & Inhibitor of ERK1/2 [16] & No effect \\
\hline CFPDP & P38 MAPK inhibitor [17] & No effect \\
\hline Tyrphostin B42 & Inhibitor of the tyrosine phosphorylation of the EGFR [21] & No effect \\
\hline AGL 2043 Tyrphostin & Inhibitor of tyrosine phosphorylation of the PDGF $\beta$-receptor) [20] & Weak activator \\
\hline Tyrphostin A25 & Inhibitor of the tyrosine phosphorylation of the EGFR [20] & Inhibitor \\
\hline \multicolumn{3}{|c|}{ Phospholipase and PKC Signaling } \\
\hline Mastoparan & Activates $\mathrm{G}_{\mathrm{i}}$ and $\mathrm{G}_{0}$-proteins [34] & No effect \\
\hline U-73122 & $\begin{array}{l}\text { Inhibits phospholipase } \mathrm{C} / \mathrm{InsP} 3 \text {-mediated } \mathrm{Ca}^{2+} \text {-mobilizing } \\
\text { pathways [35] }\end{array}$ & No effect \\
\hline PMA & Activates PKC [30] & Inhibitor \\
\hline Calphostin C & Inhibits PKC [31] & Weak activator \\
\hline \multicolumn{3}{|c|}{ Lipids and Signaling } \\
\hline Arachidonic Acid & Precursor for prostaglandins, prostacyclin, and thromboxane [36] & No effect \\
\hline Ibuprofen & Inhibitor of COX-1 and COX-2 [37] & No effect \\
\hline \multicolumn{3}{|c|}{ Steroid Hormones } \\
\hline Dexamethason & $\begin{array}{l}\text { Glucocorticoid acting through binding to a specific glucocorticoid } \\
\text { receptor [39] }\end{array}$ & Inhibitor \\
\hline Testosterone & Acting through binding to the nuclear steroid receptors [38] & Weak activator \\
\hline $17 \beta$-Estradiol & \multicolumn{2}{|l|}{ Neurotransmitters and Phosphodiesterase Inhibitor } \\
\hline Forskolin & Adenylate cyclase stimulator [40] & Inhibitor \\
\hline Isoproterenol & $\begin{array}{l}\text { Selective } \beta \text {-adrenergic agonist that stimulates adenylate cyclase } \\
\text { activity [41] }\end{array}$ & No effect \\
\hline Carbachol & Activates the Muscarinic acetylcholine receptors [42] & Inhibitor \\
\hline Histamine & Acting through various histamine receptors [43] & Inhibitor \\
\hline \multicolumn{3}{|c|}{$\begin{array}{l}\text { Acting through specific receptors [44] } \\
\text { Antioxidants and Growth Factor Scavengers }\end{array}$} \\
\hline Apigenin & Flavonoid, antioxidant compound [46] & Inhibitor \\
\hline EGCG & $\begin{array}{l}\text { Flavonoid, antioxidant compound EGCG [47], } \\
\text { able to trap growth factors such as PDGF [47] }\end{array}$ & Inhibitor \\
\hline Gangliosides GM1 & $\begin{array}{l}\text { Able to trap growth factors such as PDGF [47] } \\
\mathrm{Na}^{+} \text {and } \mathrm{Cl}^{-} \text {Channel Modulators }\end{array}$ & Inhibitor \\
\hline NPPB & $\mathrm{Cl}^{-}$channel blocker $[14]$ & Weak activator \\
\hline TTX & Voltage dependent $\mathrm{Na}^{+}$channel blocker [49] & No effect \\
\hline
\end{tabular}

tetrazolium] bis (4-methoxy-6-nitro) benzenesulphonic acid (XTT) test [6] was performed for an inhibitory and a promoting compound using ES cells from the same clone. Cells were seeded in 96 well plates and compounds were added at day 1. At day 10, XTT (Biotium Inc. Hayward CA) was added and Formazane absorbance was measured at $475 \mathrm{~nm}$. Results are expressed as $\%$ inhibition compared to control values (vehicle only).

\section{Semi-quantitative RT-PCR analysis}

Total RNA was extracted from treated EBs using Qiagen Rneasy miniKit (Qiagen GmBH, Hilden, Germany). The preparation quality was assessed by agarose-formaldehyde gel electrophoresis. A total of $2 \mu \mathrm{g}$ RNA was treated with DNase I (Amplification grade, Invitrogen Life Technologies, Carlsbad, CA, USA) before reverse transcription into cDNA by SuperscriptTM II Rnase H- free Reverse Transcriptase (Invitrogen) using random hexamer priming according to the manufacturer's instructions. PCR amplification of individual
cDNAs was accomplished in $20 \mu \mathrm{l}$ reactions containing $10 \mu \mathrm{l}$ JumpStart REDTaq ReadyMix (Sigma, St.Louis, USA), $1 \mu 1$ of synthesized cDNA and primers at a final concentration of $0.3 \mu \mathrm{M}$ each. All amplifications were performed using PCR Cycler (Eppendorf Mastercycler) under optimized conditions for each target sequence. PCR analysis was performed using specific primer pairs (see table 2 ) for genes of interest normalized against the housekeeping gene, glyceraldehyde-3-phosphate dehydrogenase (GAPDH), according to the following conditions: an initial step of $94^{\circ} \mathrm{C}$ for 2 min followed by 25-30 cycles of $94^{\circ} \mathrm{C}$ for $35 \mathrm{sec}, 60^{\circ} \mathrm{C}$ for $45 \mathrm{sec}, 72^{\circ} \mathrm{C}$ for $45 \mathrm{sec}$, and a final extension of $72^{\circ} \mathrm{C}$ for $10 \mathrm{~min}$ in a thermal cycler (Eppendorf Mastercycler). The RT-PCR products were analyzed by gel electrophoresis.

\section{Statistical analysis}

Analysis was done by the ANOVA test. Values of $p<0.05$ were considered to be statistically significant.

Cell Physiol Biochem 2006;18:303-314 
Table 2. List of primers and applied experimental RT-PCR conditions

\begin{tabular}{|c|c|c|c|c|c|}
\hline Gene & Forward Primer & Reverse Primer & $\begin{array}{l}\mathrm{T}_{\mathrm{m}} \\
\left({ }^{\circ} \mathrm{C}\right)\end{array}$ & $\begin{array}{l}\text { Size } \\
\text { (bp) }\end{array}$ & $\begin{array}{c}\text { Number of } \\
\text { cycles }\end{array}$ \\
\hline$\alpha-\mathrm{MHC}$ & GATGGCACAGAAGATGCTGA & CTGCCCCTTGGTGACATACT & 60 & 120 & 26 \\
\hline EGFP & CAGAAGAACGGCATCAAGGT & CTGGGTGCTCAGGTAGTGGT & 60 & 144 & 27 \\
\hline$\alpha-\mathrm{SMA}$ & CTATTCAGGCTGTGCTGTCC & CCAAGTCCAGACGATGAT & 60 & 107 & 30 \\
\hline PECAM-1 & GTCATGGCCATGGTCGAGTA & CTCCTCGGCGATCTTGCTGAA & 60 & 113 & 28 \\
\hline Nkx2.5 & CCACTCTCTGCTACCCACCT & CCAGGTTCAGGATGTCTTTGA & 60 & 261 & 34 \\
\hline GATA4 & TCAAACCAGAAAACGGAAGC & GTGGCATTGCTGGAGTTACC & 60 & 107 & 33 \\
\hline Troponin T & GAGGAGGTGGTGGAGGAGTA & GGCTTCTTCATCAGGACCAA & 60 & 150 & 30 \\
\hline $\mathrm{NF}-\mathrm{H}$ & GCCCAAGAGGAGATAACTGA & TTCTGTCACTCCTTCCGTCAC & 60 & 477 & 30 \\
\hline Nestin & GGAAGAAGTTCCCAGGCTTC & ATTAGGCAAGGGGAAGAGA & 60 & 138 & 30 \\
\hline GAPDH & GGTGCTGAGTATGTCGTGGA & CGGAGATGATGACCCTTTTG & 60 & 95 & 25 \\
\hline
\end{tabular}

\section{Results and Discussion}

In our recent work we focused on the development of strategies for the specific differentiation of ES cells into early cardiomyocytes and for specific cardiac lineage selection [7]. Identification of factors and signalling cascades promoting selective generation of cardiac cells from embryonic stem cells is essential for the generation and isolation of large numbers of cardiomyocytes in vitro as well as for understanding cardiac development in vivo.

Table 1 shows an overview of the small molecules identified in the present study as either promoting or inhibiting cardiomyogenesis. In the first set of experiments, 33 small molecules belonging to different cell signalling pathways were tested in parallel to investigate their effects on cardiomyogenesis according to the protocol as described in Figure 1.

Cytosolic $\mathrm{Ca}^{2+}$ is an universal signalling molecule involved in the regulation of various physiological and cellular processes such as contraction, cell motility, metabolism, gene expression, proliferation and apoptosis [8]. Therefore, we investigated the effects of different intracellular $\mathrm{Ca}^{2+}$-modulating compounds on the generation of cardiomyocytes from ES cells. Figure 2A shows the effects of cytosolic $\mathrm{Ca}^{2+}$ modulating compounds on the process of cardiomyogenesis in the ES cell system. Treatment of EBs with $100 \mathrm{nM}$ and $10 \mathrm{nM}$ Ryanodine resulted in a significant $50 \%$ and $75 \%$ increase of the EGFP fluorescence, respectively, compared to untreated cells $(=100 \%)$. Interestingly, treatment of EBs with 10 $\mu \mathrm{M}$ Verapamil caused a pronounced $94 \%$ increase of the EGFP fluorescence. The $\mathrm{EC}_{50}$ (concentration causing a $50 \%$ effect) determined from a dose-response curve covering concentrations between $1 \mathrm{nM}$ and $10 \mu \mathrm{M}$ was $1.06 \mu \mathrm{M}$. No effect was exerted by other cytosolic $\mathrm{Ca}^{2+}$ modulating agents. Ryanodine is a natural compound acting through binding to the ryanodine receptor (RyR), the $\mathrm{Ca}^{2+}$ channel of the sarcoplasmic reticulum (SR), resulting in the release of $\mathrm{Ca}^{2+}$ into the sarcoplasm. Depending on the cell type and concentration Ryanodine, induces an inhibition or an activation of the release of $\mathrm{Ca}^{2+}$ from SR [9]. Verapamil is an antagonist of the plasma membrane L-type $\mathrm{Ca}^{2+}$ channel thereby inhibiting the influx of extracellular $\mathrm{Ca}^{2+}$ into the cytosol [10]. Interestingly, in accordance with the pharmacological properties of Verapamil, spontaneous contractions of ES-cell derived cardiomyocytes were totally inhibited when Verapamil was present at late stages of cardiac differentiation. In contrast to Verapamil, the synthetic L-type $\mathrm{Ca}^{2+}$ channel agonist S-(-)-Bay $\mathrm{K} 8644$ that acts as an $\mathrm{Ca}^{2+}$ channel agonist in various cell types causing an elevation of $\left[\mathrm{Ca}^{2+}\right]_{i}$ [11] did not affect cardiomyogenesis. Caffeine, which activates the RyR resulting in a release of $\mathrm{Ca}^{2+}$ from SR [12], did not affect cardiomyogenesis in ES cells. Thapsigargin (10 $\mathrm{nM})$, a selective SERCA inhibitor [13], thereby elevating the cytosolic $\mathrm{Ca}^{2+}$, had also no effects on cardiac cell formation. Thapsigargin at $100 \mathrm{nM}$ was toxic to the cells. From these results we conclude that cytosolic $\mathrm{Ca}^{2+}$ is involved in the differentiation of cardiomyocytes from ES cells and that $\left[\mathrm{Ca}^{2+}\right]_{\mathrm{i}}$ lowering agents such as Verapamil and Ryanodine promote cardiomyogenesis even if the physiological activity of beating is inhibited. Amiloride, a blocker of the $\mathrm{Na}^{+} / \mathrm{H}^{+}$ antiport [14] did not show any effect on cardiomyogenesis (Fig. 2A).

The effects of small molecules belonging to the

Sachinidis/Schwengberg/Hippler-Altenburg/Mariappan/Kamisetti/ Seelig/Berkessel/Hescheler 
Fig. 1. Differentiation protocol for the identification of small molecules affecting cardiomyogenesis. To start differentiation, ES cells were cultured in suspension for $24 \mathrm{~h}$ to form EBs. About fifty EB were transferred to each well of bacterial 6 well plates and test compounds such as Verapamil were added. On day five, half of the medium was replaced by fresh medium and fresh test compounds were added. On day 14, EBs on each plate were counted, lysed and fluorescence in the lysates was measured at an excitation wavelength of $476 \mathrm{~nm}$ and an emission wavelength of $508 \mathrm{~nm}$. Photomicrographs were taken on day 14 from EBs plated on 24 well tissue culture plate on day 7 of differentiation.

"protein phosphorylation pathway category" are shown in Figure 2B. Exposure of cells to $2 \mu \mathrm{M}$ Genistein, a general inhibitor of tyrosine kinases acting through a competitive inhibition with respect to ATP [15], resulted in a $30 \%$ decrease of the EGFP fluorescence. PD 98059 , an inhibitor of the p42/p44 MAP kinase ERK 1/2 [16], and 2-(4-Chlorophenyl)-4-(4-fluorophenyl)-5-pyridin-4-yl1,2-dihydropyrazol-3-one (CFPDP), a p38 MAP Kinase inhibitor [17], did not influence cardiomyogenesis.

A slight increase of $36 \%$ was observed after treatment of EBs with $10 \mu \mathrm{M}$ 1,2-Dimethyl-6-(2-thienyl)imidazolo[5, 4-g]quinoxaline (Tyrphostin AGL 2043), a potent selective ATP-competitive and reversible inhibitor of PDGF $\beta$-receptor [18]. To identify growth factors promoting cardiac development we recently established a new differentiation protocol using a defined serumreplacement medium (SRM) in combination with Dulbecco's Modified Eagle Medium (DMEM). Using SRM/DMEM, we obtained an increase of $\alpha$-MHC in relation to $0,2 \%$ foetal calf serum (FCS)/DMEM. Stimulation of EBs with PDGF-BB in the presence of SRM/DMEM resulted in a further enhancement in comparison with the SRM/DMEM-induced increase of $\alpha$-MHC. Under these conditions, stimulation of the cells with $10-20 \%$ foetal calf serum totally repressed expression of $\alpha-\mathrm{MHC}$ [19]. In the present study FCS has been used in all differentiation steps. Using the protocol described in Figure 1, $50 \mathrm{ng} / \mathrm{ml}$ PDGF-BB had no effect on

Small Molecules and Cardiomyogenesis cardiomyogenesis since FCS was available in the medium during all differentiation steps. Under serum containing conditions, it is not possible to identify a cardiomyogenic effect of PDGF-BB and probably of other growth factors. This phenomenon is well known also by proliferation studies. A proliferative effect of PDGF-BB can only be detected in the absence of serum and after serum starvation for at least 24 hours. The slight stimulatory effect of Tyrphostin AGL 2043 might be explained by possible side effects of this molecule. $10 \mu \mathrm{M} \alpha$-Cyano(3,4,5-trihydroxy)cinnamonitrile (Tyrphostin A25), a competitive inhibitor of the tyrosine phosphorylation of the epidermal growth factor receptor [20], caused a 50\% reduction of cardiomyogenesis. Similarly, $\alpha$-Cyano- $(3,4-$ dihydroxy)-N-benzylcinnamide (Tyrphostin B42), another inhibitor of the tyrosine phosphorylation of the epidermal growth factor receptor [21], also caused a reduction of the amount of cardiac cells. These results suggest that tyrosine kinases receptors, especially the EGF receptors, are involved in the differentiation of ES cells towards cardiomyocytes. In this context, it has been shown that Neuregulin, a member of the EGF family, is involved in cardiac development in vivo [22].

Notably, exposure of EBs to $10 \mu \mathrm{M}$ and $1 \mu \mathrm{M}$ Cyclosporin A caused a $140 \%$ and $60 \%$ increase of the EGFP fluorescence, respectively. The $\mathrm{EC}_{50}$ determined from a dose-response-curve covering concentrations between $1 \mathrm{nM}$ and $10 \mu \mathrm{M}$ was $0.36 \mu \mathrm{M}$. Cyclosporin $\mathrm{A}$ is 

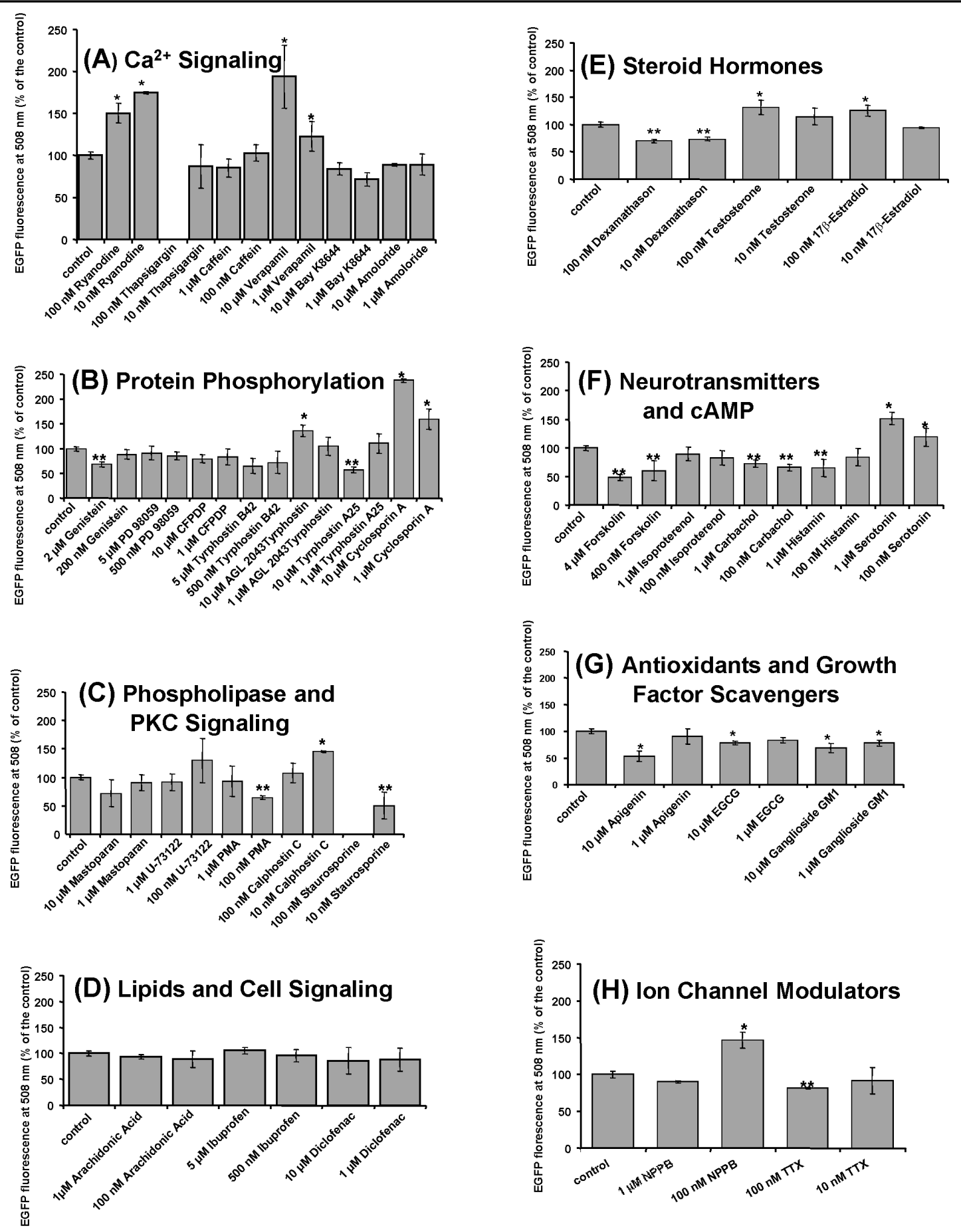

Fig. 2. Effects of various small signalling molecules on cardiomyogenesis in ES cells. Differentiation, addition of test compounds, and quantification of cardiac cells by EGFP-expression has been performed as indicated in Fig. 1. Values from three independent experiments (mean $\pm \mathrm{SD}, \mathrm{n}=3$ ), each performed in triplicates, were expressed as percent of control values (vehicle) $(=100 \%)$. Values are normalized to the number of EBs. Both, a significant increase $(* \mathrm{P}<0.05)$ and decrease $(* * \mathrm{P}<0.05)$ of values, compared to vehicle controls, represent an effect on generation of cardiac cells.

an amino acid cyclic peptide used as an immunosuppressant compound. Complexes of Cyclosporin A with the immunophillin Cyclophilin A within the cell inhibit the $\mathrm{Ca}^{2+}$-and calmodulin-dependent protein phosphatase 2B (Calcineurin) [23, 24]. Transcription factors of the NF/AT family, which act as substrates for

Sachinidis/Schwengberg/Hippler-Altenburg/Mariappan/Kamisetti/ Seelig/Berkessel/Hescheler 
Fig. 3. Effects of Verapamil $(10 \mu \mathrm{M})$ and Forskolin (400 nM) on the Expression of EGFP normalized to the number of EBs or to the protein content as well as on the formazan formation as a marker of the viability of the cells. Differentiation, addition of test compounds, and quantification of cardiac cells by EGFPexpression has been performed as indicated in Fig. 1. Values from three independent experiments (mean $\pm \mathrm{SD}, \mathrm{n}=3$ ), each performed in triplicates, were expressed as percent of control values (vehicle) $(=100 \%)$. Both, a significant increase $(* \mathrm{P}<0.05)$ and decrease $\left(\mathrm{P}^{* *}<0.05\right)$ of values, compared to vehicle controls, represent an effect on generation of cardiac cells.

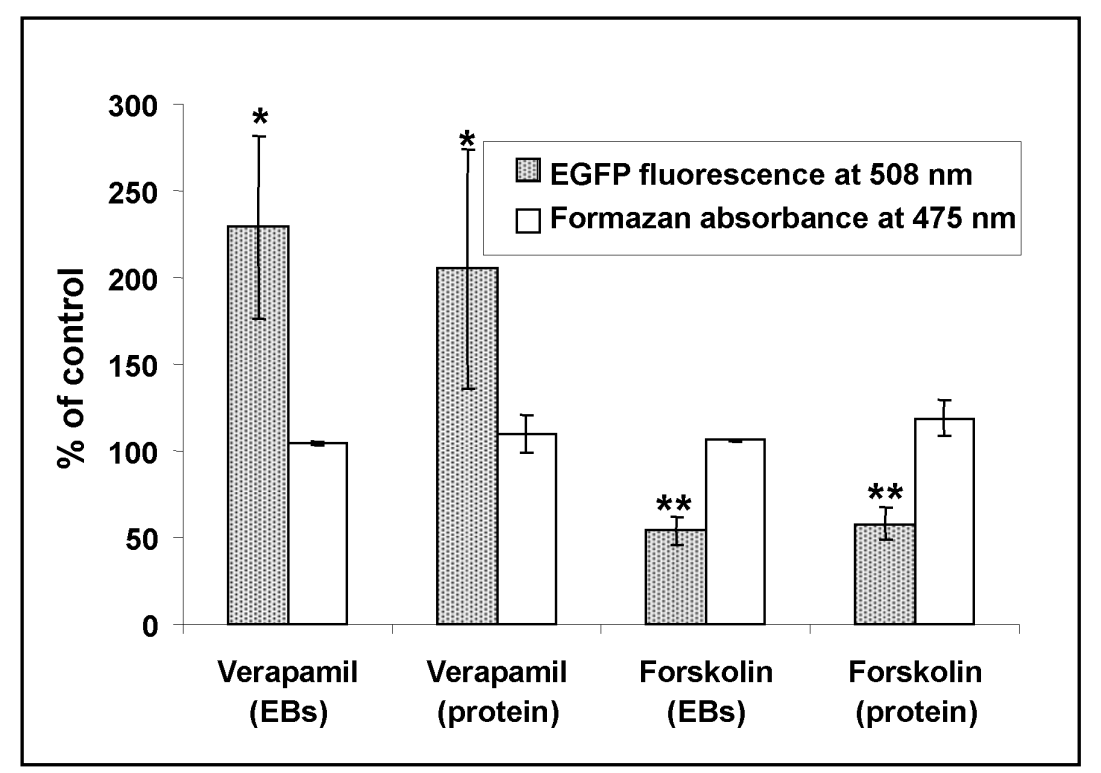

Calcineurin, are therefore also inhibited by Cyclosporin A. Interestingly, there is increasing evidence that Calcineurin is also involved in the regulation of other cellular processes such as apoptosis, embryonic development, and cancer [8, 24-27], as well as cardiac valve formation and cardiac hypertrophy $[28,29]$.

Figure 2C shows the effects of small molecules belonging to the "phospolipase and protein kinase" category. Staurosporine at a concentration of $100 \mathrm{nM}$ caused cell death suggesting a general toxic effect of Staurosporine. Phorbol-12-myristate-13-acetat (PMA), one of the most commonly-used phorbol ester, activating protein kinase $\mathrm{C}$ (PKC) in vivo and in vitro [30] at a concentration of $100 \mathrm{nM}$, induced a $40 \%$ decrease of cardiomyogenesis whereas Calphostin $\mathrm{C}$, a highly specific inhibitor of PKC [31], caused a weak increase of cardiomyogenesis at a concentration of $10 \mathrm{nM}$. These findings suggest that the activation of PKC may be a negative regulator of cardiomyogenesis. In agreement with our findings, it has been shown recently that differentiation of embryonic stem cells into beating cardiomyocytes is dependent on down regulation of the $\mathrm{PKC} \beta$ and $\mathrm{PKC} \zeta$ isoforms [32]. As shown in Figure 2C, $100 \mathrm{nMCalphostin}$ did not influence the EGFP expression. This finding suggest that Calphostin $\mathrm{C}$ at higher concentrations than $10 \mathrm{nM}$ might exerts effects counteracting the cardiac promoting effects of this molecule. Recently, Ventura et al. [33] reported that 1 $\mu \mathrm{M}$ Calphostin completely inhibited cardiac differentiation. However, since we observed a slight increase of cardiogenesis only at a concentration of $10 \mathrm{nM}$, effects seen at higher concentrations (e.g. inhibition of cardiac

Small Molecules and Cardiomyogenesis differentiation observed by Ventura et al.) may be attributed to side effects occurring at such concentrations. Mastoparan is a cell-permeable peptide directly activating $G_{\mathrm{i}}$ and $\mathrm{G}_{\mathrm{o}}$ and in less extent $\mathrm{G}_{\mathrm{s}}$ pertussis toxin-sensitive G-proteins [34]. 1-[6-(17ß-3-Methoxyestra-1,3,5(10))trien-17-yl)amino)hexyl]-1H-pyrrole-2,5-dione(U-73122) inhibits agonist-induced phospholipase $\mathrm{C} /$ inositol 1,4,5trisphosphate $\left(\mathrm{InsP}_{3}\right)$-mediated $\mathrm{Ca}^{2+}$-mobilizing pathways in various cell types [35]. However, neither Mastoparan nor U-73122 had an effect on cardiomyogenesis in ES cells suggesting a minor role of these pathways for cardiomyogenesis.

Arachidonic acid, generated by the Phospholipase A2-induced hydrolysis of the membrane phospholipids, is a precursor for prostaglandins, prostacyclin, and thromboxane [36]. Ibuprofen and Diclofenac are competitive inhibitors of cyclooxygenase (COX)-1 and COX-2, which are enzymes of the eicosanoid metabolism using arachidonic acid as substrate [37]. As shown in Fig. 2D, neither arachidonic acid itself nor the cyclooxygenase inhibitors had any effects on cardiomyogenesis.

As demonstrated in Figure 2E, treatment of EBs

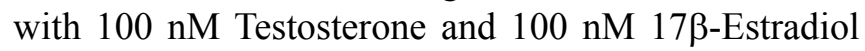
resulted in a weak 30\% increase, whereas Dexamethason at 100 and $10 \mathrm{nM}$ caused a moderate $30 \%$ decrease in EGFP fluorescence. The biological actions of the sex hormones testosterone and 17 $\beta$-Estradiol are predominantly exerted through binding to the nuclear steroid receptors that function as ligand-activated transcription factors [38]. However, sex hormones are also able to stimulate various signal transduction pathways 
Fig. 4. Effects of Verapamil and Cyclosporin A on the expression of Nkx2.5, GATA4 and Troponin T. A, Addition of Verapamil or Cyclosporin A (each $1 \mu \mathrm{M}$ ) was performed in medium containing 1-day old EBs and RNA was isolated at different time points according to the above protocol. B, To determine the expression of $\mathrm{Nkx} 2.5$, GATA4 and Troponin T, total RNA was isolated from EBs and RT-PCR has been performed using the appropriate primers (see table 2). One experiment from two independent experiments with similar results.

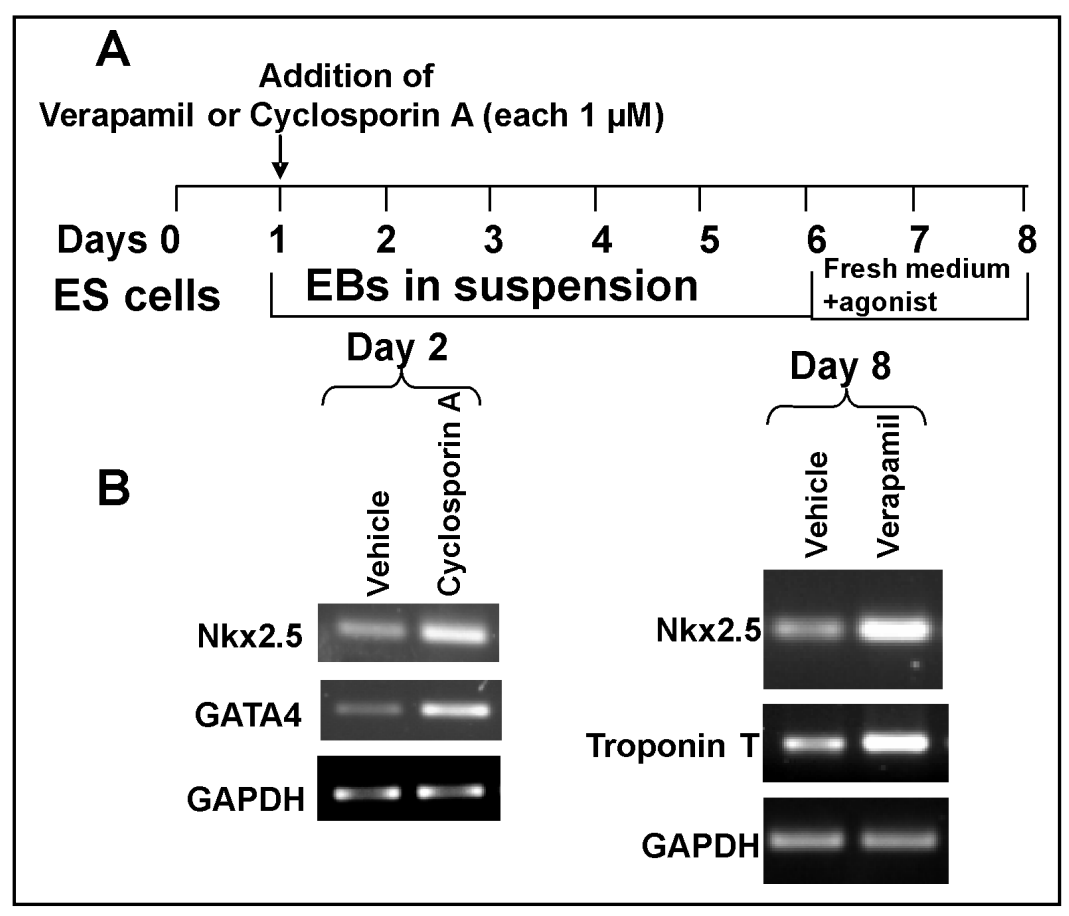

Fig. 5. Effects of Verapamil and Cyclosporin A on the expression of Nestin and NF-H. A, Addition of Verapamil or Cyclosporin A (each $1 \mu \mathrm{M}$ ) was performed in medium containing 1-day old EBs according to the protocol as described in Figure 4. To determine the expression of Nestin and NF-H, total RNA was isolated after 1 and 8 days from EBs and RT-PCR has been performed using the primers and conditions as described in table 2 .

such as kinase-signalling cascades via receptors located in the plasma membranes [38]. Our findings demonstrate that both testosterone and $17 \beta$-estradiol had only a weak effect on cardiomyogenesis in ES cells. In contrast, Dexamethasone, a chemically synthesized corticoid, inhibited cardiomyogenesis in ES cells. Dexamethasone belongs to the glucocorticoids that are potent antiinflammatory drugs acting through binding to a specific glucocorticoid receptor (GR) [39].

Results from treatment of EBs with compounds belonging to neurotransmitters and cAMP - increasing compounds are shown in Fig. 2F. Forskolin $(4 \mu \mathrm{M})$, which is an adenylate cyclase stimulator increasing intracellular cAMP [40], significantly reduced cardiomyogenesis by $50 \%$, whereas Isoproterenol, a $\beta$-adrenergic agonist that stimulates adenylate cyclase activity [41], did not influence cardiomyogenesis. Carbachol $(1 \mu \mathrm{M})$, an activator of the muscarinic acetylcholine receptors [42], and histamine $(1 \mu \mathrm{M})$, which is a neurotransmitter acting through various histamine receptors [43], also inhibits cardiomyogenesis by $30 \%$ and $35 \%$, respectively. Serotonin, another

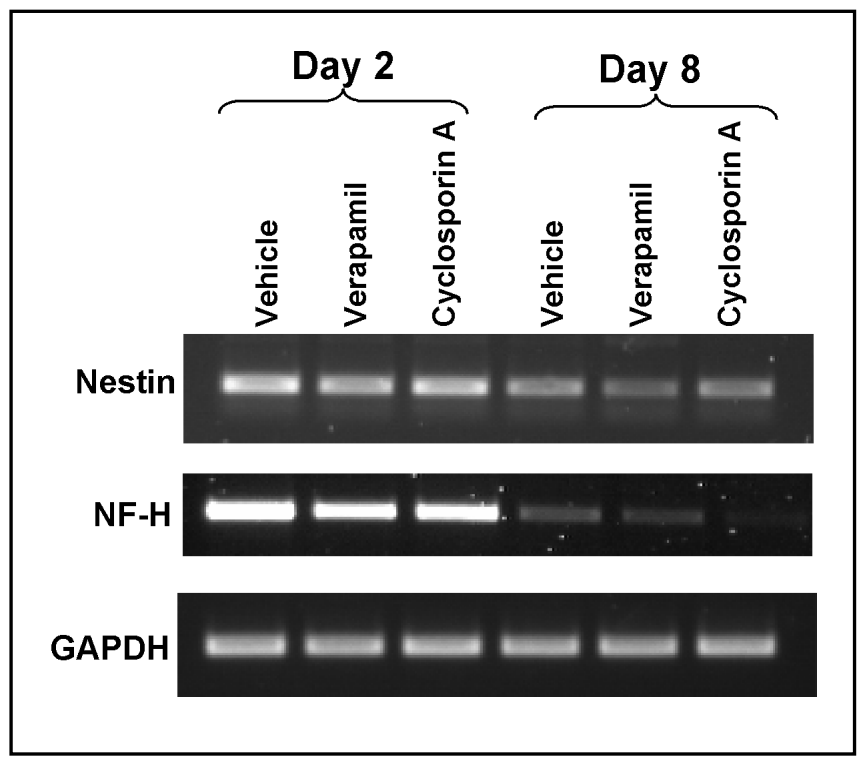

neurotransmitter acting through various subtypes of specific 5HT-receptors [44], caused a 52\% increase of EGFP fluorescence at $1 \mu \mathrm{M}$. In this context, there is an evidence that serotonin may play a role in cardiac morphogenesis [45].

Treatment of EBs with the flavonoids antioxidant compounds Apigenin [46], Epigallocatechin Gallate (EGCG) [47] and the glycolipid gangliosides GM1, each at a concentration of $10 \mu \mathrm{M}$, resulted in a $47 \%, 21 \%$ and $30 \%$ decrease of EGFP fluorescence, respectively (Fig. $2 \mathrm{G})$. However, the anti-cardiomyogenic activity of Apigenin was more pronounced than that of EGCG. These results are supported by findings demonstrating that

Sachinidis/Schwengberg/Hippler-Altenburg/Mariappan/Kamisetti/ Seelig/Berkessel/Hescheler 
Fig. 6. Simultaneous Stimulation of EBs with Verapamil and Cyclosporin A (each $1 \mu \mathrm{M}$ ). Stimulation has been performed according to the protocol as described in Figure 1. On day 14, EBs on each plate were counted, lysed and fluorescence in the lysates was measured at an excitation wavelength of $476 \mathrm{~nm}$ and an emission wavelength of $508 \mathrm{~nm}$. Values from three independent experiments (mean $\pm \mathrm{SD}$ ), each performed in triplicates, were expressed as percent of control values (vehicle) $(=100 \%)$. Values are normalized to the number of EBs. A significant increase of values $(* \mathrm{P}<0.05)$, compared to vehicle controls, represent an effect on generation of cardiac cells. No statistical differences were observed between the effect (Verapamil + Cyclosporin) versus Verapamil or Cyclosporin alone.

incubation of EBs with $\mathrm{H}_{2} \mathrm{O}_{2}$ enhances cardiomyogenesis, whereas radical scavengers exerted inhibitory effects [48]. Also, like EGCG [47], the glycolipid Ganglioside GM1 that is able to trap growth factors such as PDGF [47], exerted anti-cardiomyogenic effects. Finally, the $\mathrm{Cl}^{-}$ channel blocker NPPB [14] (100 nM) induced a 50\% increase of cardiomyogenesis suggesting a possible role of the $\mathrm{Cl}^{-}$channel in cardiomyogenesis whereas tetrodotoxin (TTX), a blocker of the voltage dependent $\mathrm{Na}^{+}$channel $[14,49]$ at a concentration of $100 \mathrm{nM}$ resulted in a weak decrease of $15 \%$ (Fig. $2 \mathrm{H}$ ).

To clarify if compounds showing an inhibitory effect on cardiomyogenesis are cytotoxic, a sodium 3'-[1-phenylaminocarbonyl-3,4-tetrazolium] bis (4-methoxy-6nitro)benzenesulphonic acid (XTT) cytotoxicity assay was performed for one potent inhibiting (Forskolin) and one promoting compound (Verapamil). As shown in Figure 3, no cytotoxicity was observed at concentrations used in the present study. Also, EGFP fluorescence in cell lysates was not only normalized to number of EBs, but also to protein content of cell lysates, since a cytotoxic or mitogenic action of a compound would influence the size of the EBs. As demonstrated in Fig. 3, both calculations gave similar results. These findings demonstrate that the inhibitory effects of Forskolin can not be attributed to a possible toxic effect of Forskolin. However, possible toxic effects of other molecules used in this study such as Tyrphostin A25 can not be excluded.

To demonstrate whether the cardiomyogenic effect of Verapamil and Cyclosporin A determined at day 14 (Fig. 2, 3) is accompanied by an increased expression level of the cardiac specific transcription factors GATA4 and Nkx2.5 [7], the expression level of GATA4 and $\mathrm{Nkx} 2.5$ has been determined after stimulation of 1-day old EBs (Fig. 4).

Small Molecules and Cardiomyogenesis

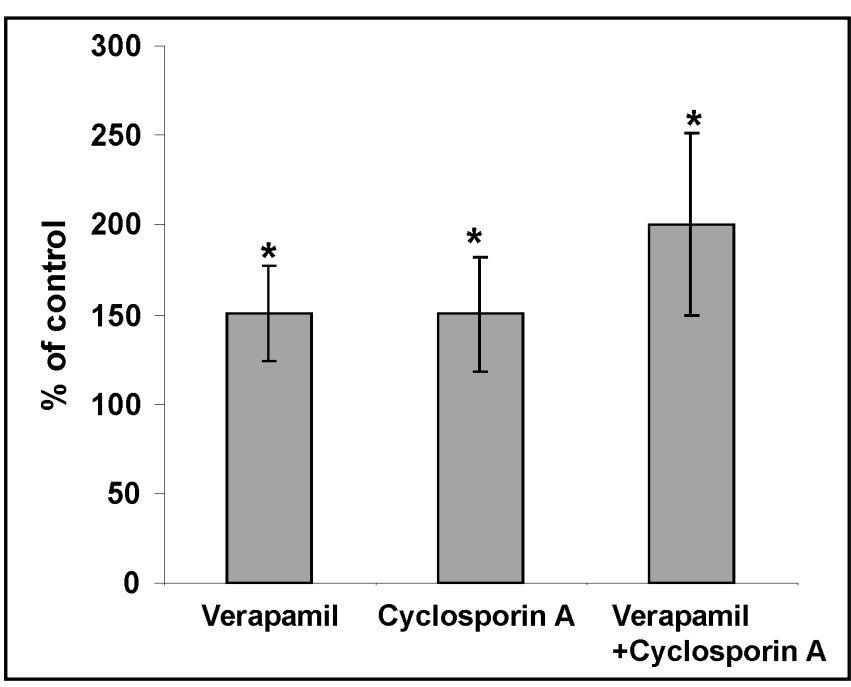

Compared to vehicle-treated EBs, an increase in the expression of $\mathrm{NKx} 2.5$ and GATA4 was found only after 1 day of stimulation with $1 \mu \mathrm{M}$ Cyclosporin A (Fig. 4). Even after 8 days, no increase in the expression level of Troponin $\mathrm{T}$ could be observed. In contrast, after stimulation with $1 \mu \mathrm{M}$ Verapamil, an increase in the expression level of $\mathrm{Nkx} 2.5$ could be observed only at day 8. This effect was accompanied with an increase in the expression level of Troponin T (Fig. 4). These findings demonstrate that the mode of action of both compounds seems to be different, although leading to the same effect (increase in the amount of cardiac cells). The detailed mechanisms by which both agonists exert their effects remain to be elucidated.

In parallel, we determined the expression of the neuronal cell specific genes Neurofilament $\mathrm{H}$ (NF-H) and Nestin. As shown in Figure 5 both agonists had no effect on the expression of Nestin. Only a weak decrease of the expression of NF-H was observed by Cyclosporin A. To test whether an additive or synergistic effect can be observed, Cyclosporin and Verapamil were added together (both at $1 \mu \mathrm{M}$ ) using the protocol described in Figure 1. In 3 individual experiments, no statistically (Verapamil or Cyclosporine A effect versus Verapamil plus Cyclosporine A effect) synergistic or additive effect of the combinational treatment can be observed (Figure 6) suggesting that the compounds exert their effect at different points of the differentiation pathways.

In order to examine whether the cardiomyogenesispromoting effects of Verapamil and Cyclosporin A are due to enhanced differentiation of ES cells towards cardiomyocytes or a result of enhanced proliferation of early cardiomyocytes, addition of Verapamil and Cyclosporin A was performed at early and late differentiation stage EBs for $48 \mathrm{~h}$ according to the protocol

Cell Physiol Biochem 2006;18:303-314 
Fig. 7. Stimulation of early and late differentiation state EBs with Verapamil and Cyclosporin A. A, Addition of $1 \mu \mathrm{M}$ Verapamil or $1 \mu \mathrm{M}$ Cyclosporin A was performed at different time points (day $1,3,5,7)$ according to the above protocol. At each time point, after $48 \mathrm{~h}$, medium containing Verapamil or Cyclosporin A was removed, EBs were washed 2 times with differentiation medium, and fresh medium was added to the cells without Verapamil (B) or Cyclosporin A (C). Experiments were terminated at day 14 and EGFP fluorescence of the $\alpha-\mathrm{MHC}$ expression was measured. Fluorescence values of the expression of $\alpha$-MHC from two independent experiments (mean $\pm \mathrm{SD}, \mathrm{n}=2$ ), each performed in duplicates, were expressed as percent of control values (vehicle) $(=100 \%)$. In parallel, expression of $\alpha-\mathrm{MHC}$, EGFP, PECAM-1 and $\alpha$-SMA has been determined after isolation of total RNA from EBs (1-day, 3-days, 5-days and 7-days after incubation with Verapamil or Cyclosporine A for $48 \mathrm{~h}$ ) by RTPCR using the appropriate primers (see table 2). Values are normalized to the number of EBs.
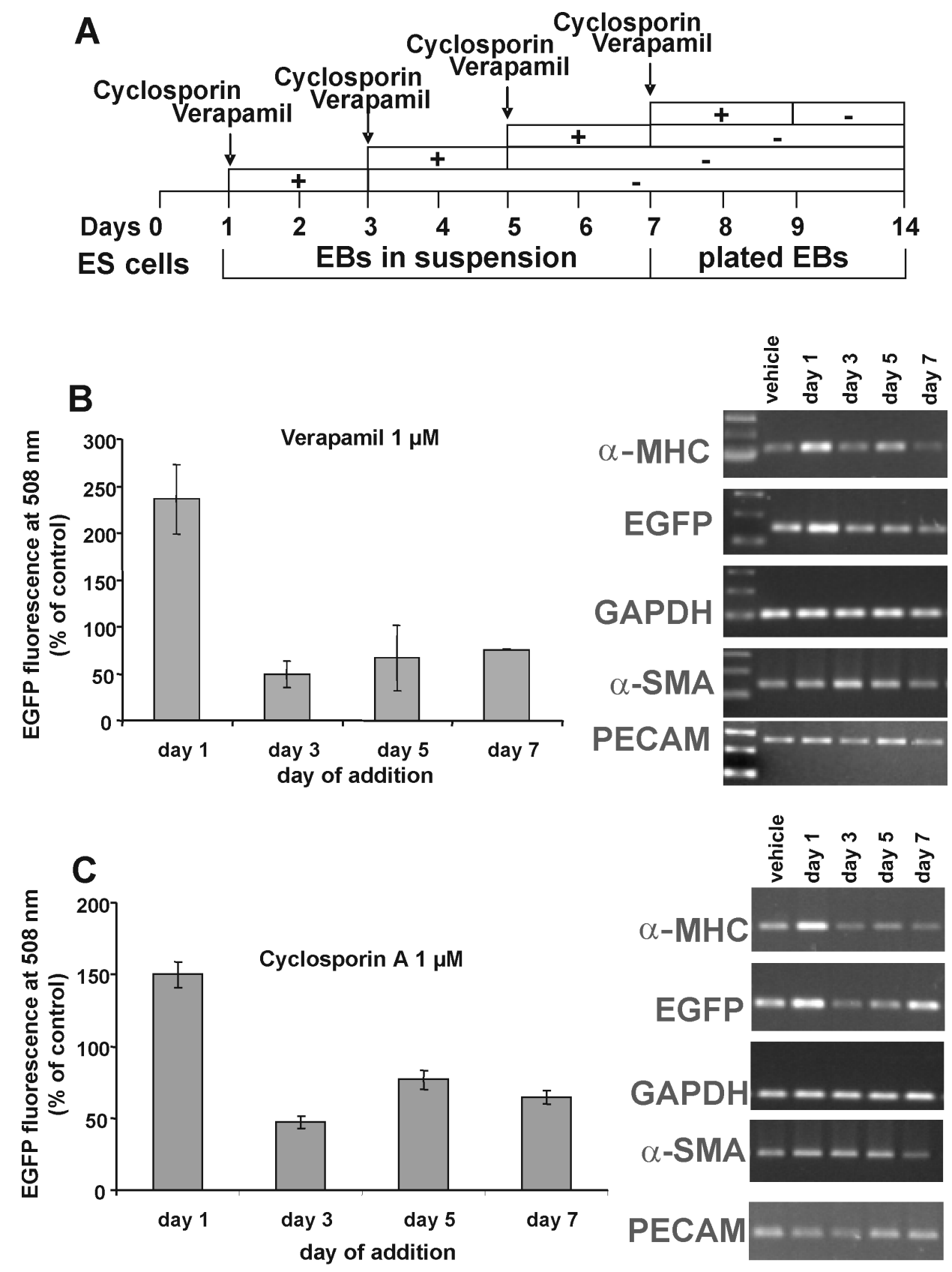

shown in Fig. 7A. EGFP fluorescence was determined by fluorescence spectroscopy or by microscopy at day 14. Although in the screening study maximal effects were observed at $10 \mu \mathrm{M}$, both agonists were used at a concentration of $1 \mu \mathrm{M}$ in these experiments to avoid possible side effects. As demonstrated in Fig. 7B, the addition of $1 \mu \mathrm{M}$ Verapamil resulted in an increase of cardiomyogenesis only if the compound was added on day 1. No promoting effect of Verapamil was observed if the compound is added at the other time points (day 3 ,
5, or 7) for $48 \mathrm{~h}$. In accordance with these findings, a parallel increase of the expression of the $\alpha-M H C$ and EGFP mRNA was observed. Similar results were observed after addition of $1 \mu \mathrm{M}$ Cyclosporin A(Fig. 7C). Again, only the addition of $1 \mu \mathrm{M}$ Cyclosporin A at day 1 resulted in an increase of cardiomyogenesis that correlated with an increase of $\alpha-M H C$ and $E G F P$ mRNA expression. The expression of PECAM-1 mRNA as a marker for endothelial cells and of $\alpha$-smooth muscle actin $(\alpha-S M A)$ mRNA as a marker for SMC was not increased

Sachinidis/Schwengberg/Hippler-Altenburg/Mariappan/Kamisetti/ Seelig/Berkessel/Hescheler 
by the addition of Verapamil or Cyclosporin A. An inhibition of spontaneous contractions of the cardiomyocytes was not observed when Verapamil was added on day 1, 3 , or 5 , whereas the addition on day 7 (all for $48 \mathrm{~h}$ ) completely abolished the beating activity measured on day 14 (see supplementary materials, film Verapamil.avi). No influence on spontaneous contractions was observed after the addition of Cyclosporin A (see supplementary material, Cyclosporin A.avi). Since the most prominent effect in promoting cardiomyogenesis was observed after stimulation of 1-day old EBs for 48h, and within this time period no cardiac cells can be developed [7], we conclude that the cardiomyogenic effects of both compounds are exerted by increasing the differentiation capacity of the ES cells towards cardiac cells. In accordance with these findings a parallel increase in the expression of the $\alpha$ MHC and EGFP mRNA was observed. It is notably that both compounds act on intracellular $\mathrm{Ca}^{2+}$ signalling, although at different levels of the signalling cascade. Verapamil antagonizes the L-type $\mathrm{Ca}^{2+}$ channel, whereas Cyclosporin A inhibits Calcineurin and NF/AT transcription factors [28, 29]. It is known that constitutive active Calcineurin leads to cardiac hypertrophy, and that a certain subtype of NF/AT is crucial for correct cardiac valve formation $[28,29]$.
Our results suggests that the generation of early cardiac progenitors is correlated to $\mathrm{Ca}^{2+}$ signalling and the Calcineurin pathway and that inhibition of both signalling pathways at different levels resulted in an increased capacity of ES cells to differentiate into cardiomyocytes. Since both agonists had no effect on the expression of PECAM-1, $\alpha$-SMA, NF-H and Nestin, Verapamil and Cyclosporin A induce preferable cardiomyogenesis. Although we succeeded in identification of a distinct signal transduction pathway promoting cardiomyogenesis, the detailed intracellular mechanisms of the agonists remain to be elucidated in further studies.

\section{Acknowledgements}

We thank Isabella Kopp, Josef Tenelsen and Simone Wagner for excellent technical assistance as well as Eugen Kolossov for the cloning of the cardiac-specific reporter gene. This work was supported by a grant from the European Community ( $6^{\text {th }}$ Framework Programme, Thematic Priority: Life sciences, genomics and biotechnology for health, Project FunGenES LSHG-CT2003-503494).

\section{References}

Odorico JS, Kaufman DS, Thomson JA: Multilineage differentiation from human embryonic stem cell lines. Stem Cells 2001;19:193-204.

-2 Winkler J, Hescheler J, Sachinidis A: Embryonic stem cells for basic research and potential clinical applications in cardiology. Biochim Biophys Acta 2005;1740:240-248.

-3 Smith AG, Heath JK, Donaldson DD, Wong GG, Moreau J, Stahl M, Rogers D: Inhibition of pluripotential embryonic stem cell differentiation by purified polypeptides. Nature 1988;336:688-690. Itskovitz-Eldor J, Schuldiner M, Karsenti D, Eden A, Yanuka O, Amit M, Soreq H, Benvenisty N: Differentiation of human embryonic stem cells into embryoid bodies compromising the three embryonic germ layers. Mol Med $>8$ 2000;6:88-95.
Kolossov E, Lu Z, Drobinskaya I, Gassanov N, Duan Y, Sauer H, Manzke $\mathrm{O}$, Bloch W, Bohlen H, Hescheler J, Fleischmann BK: Identification and characterization of embryonic stem cellderived pacemaker and atrial cardiomyocytes. FASEB J 2005;19:577579.

Jost LM, Kirkwood JM, Whiteside TL: Improved short- and long-term XTTbased colorimetric cellular cytotoxicity assay for melanoma and other tumor cells. J Immunol Methods 1992;147:153165.

Sachinidis A, Fleischmann BK, Kolossov E, Wartenberg M, Sauer H, Hescheler J: Cardiac specific differentiation of mouse embryonic stem cells. Cardiovasc Res 2003;58:278-291.

Groenendyk J, Lynch J, Michalak M: Calreticulin, $\mathrm{Ca} 2+$, and calcineurin signaling from the endoplasmic reticulum. Mol Cells 2004;17:383-389.
Feher JJ,.Lipford GB: Mechanism of action of ryanodine on cardiac sarcoplasmic reticulum. Biochim Biophys Acta 1985;813:77-86.

Striessnig J, Grabner M, Mitterdorfer J, Hering S, Sinnegger MJ, Glossmann H: Structural basis of drug binding to $\mathrm{L} \mathrm{Ca} 2+$ channels. Trends Pharmacol Sci 1998; 19:108-115.

Rampe D,.Triggle DJ: New advances in molecular pharmacology of $\mathrm{Ca} 2+$ channels. Trends Pharmacol Sci 1989;10:388-389.

McCarron JG, Bradley KN, MacMillan D, Muir TC: Sarcolemma agonist-induced interactions between InsP3 and ryanodine receptors in $\mathrm{Ca} 2+$ oscillations and waves in smooth muscle. Biochem Soc Trans 2003;31:920-924. 
13 Tsuda T, Kusui T, Jensen RT: Neuromedin $B$ receptor activation causes tyrosine phosphorylation of p125FAK by a phospholipase $\mathrm{C}$ independent mechanism which requires $\mathrm{p} 21$ rho and integrity of the actin cytoskeleton. Biochemistry $>25$ 1997;36:16328-16337.

14 Kirk K, Ellory JC, Young JD: Transport of organic substrates via a volume- 26 activated channel. J Biol Chem 1992;267:23475-23478.

$>15$ Migita K, Eguchi K, Kawabe Y, >27 Mizokami A, Tsukada T, Nagataki S: Prevention of anti-CD3 monoclonal antibody-induced thymic apoptosis by protein tyrosine kinase inhibitors. J Immunol 1994;153:3457-3465.

Dudley DT, Pang L, Decker SJ, Bridges 28

AJ, Saltiel AR: A synthetic inhibitor of the mitogen-activated protein kinase cascade. Proc Natl Acad Sci USA 1995;92:7686-7689.

17 de Laszlo SE, Visco D, Agarwal L, Chang L, Chin J, Croft G, Forsyth A, Fletcher D, Frantz B, Hacker C, Hanlon W, Harper C, Kostura M, Li B, Luell S, MacCoss M, Mantlo N, O’Neill EA, Orevillo C, Pang M, Parsons J, Rolando A, Sahly Y, Sidler K, O’Keefe SJ: Pyrroles and other heterocycles as inhibitors of p38 kinase. Bioorg Med Chem Lett $>30$ 1998;8:2689-2694.

$>18$ Gazit A, Yaish P, Gilon C, Levitzki A: Tyrphostins I: synthesis and biological activity of protein tyrosine kinase inhibitors. J Med Chem 1989;32:23442352.

Sachinidis A, Gissel C, Nierhoff D, Hippler-Altenburg R, Sauer $H$, Wartenberg M, Hescheler J: Identification of plateled-derived growth factor-BB as cardiogenesis-inducing factor in mouse embryonic stem cells under serum-free conditions. Cell Physiol Biochem 2003;13:423-429.

$>20$ Gazit A, Yee K, Uecker A, Bohmer FD, Sjoblom T, Ostman A, Waltenberger J, Golomb G, Banai S, Heinrich MC, Levitzki A: Tricyclic quinoxalines as potent kinase inhibitors of PDGFR kinase, Flt3 and Kit. Bioorg Med Chem 2003;11:2007-2018.

21 Jaleel M, Shenoy AR, Visweswariah SS: 34 Tyrphostins are inhibitors of guanylyl and adenylyl cyclases. 2004;43:82478255 .

$\checkmark 22$ Meyer D,.Birchmeier C: Multiple essential functions of neuregulin in development. Nature 1995;378:386- 35 390 .

D23 Martinez-Martinez S,.Redondo JM: Inhibitors of the calcineurin/NFAT pathway. Curr Med Chem 2004;11:9971007 .
24 Molkentin JD: Calcineurin-NFAT $>36$ signaling regulates the cardiac hypertrophic response in coordination with the MAPKs. Cardiovasc Res 2004;63:467-475.

Crabtree GR: Calcium, calcineurin, and $>37$ the control of transcription. J Biol Chem 2001;276:2313-2316.

Crabtree GR,.Olson EN: NFAT signaling: choreographing the social lives of cells. Cell 2002;109 Suppl:S67-S79.

Graef IA, Wang F, Charron F, Chen L, Neilson J, Tessier-Lavigne M, Crabtree GR: Neurotrophins and netrins require $>39$ calcineurin/NFAT signaling to stimulate outgrowth of embryonic axons. Cell 2003;113:657-670.

de la Pompa JL, Timmerman LA, 40 Takimoto H, Yoshida H, Elia AJ, Samper E, Potter J, Wakeham A, Marengere L, Langille BL, Crabtree GR, Mak TW: Role 41 of the NF-ATc transcription factor in morphogenesis of cardiac valves and septum. Nature 1998;392:182-186.

29 Ranger AM, Grusby MJ, Hodge MR, Gravallese EM, de la Brousse FC, Hoey T, Mickanin C, Baldwin HS, Glimcher
LH: The transcription factor NF-ATc is essential for cardiac valve formation. Nature 1998;392:186-190.

Liu WS,.Heckman CA: The sevenfold way of $\mathrm{PKC}$ regulation. Cell Signal $>43$ 1998;10:529-542.

31 Jarvis WD, Turner AJ, Povirk LF, Traylor RS, Grant S: Induction of apoptotic DNA 44 fragmentation and cell death in HL-60 human promyelocytic leukemia cells by pharmacological inhibitors of protein $>45$ kinase C. Cancer Res 1994;54:17071714.

32 Zhou X, Quann E, Gallicano GI: Differentiation of nonbeating embryonic 46 stem cells into beating cardiomyocytes is dependent on downregulation of $\mathrm{PKC}[$ beta] and [zeta] in concert with upregulation of PKC[var epsilon]. Dev Biol 2003;255:407-422.

\$3 Ventura C, Zinellu E, Maninchedda E, Fadda M, Maioli M: Protein kinase C signaling transduces endorphin-primed cardiogenesis in GTR1 embryonic stem cells. Circ Res 2003;92:617-622.

Hirata Y, Nakahata N, Ohizumi Y: Identification of a 97-kDa mastoparan- 48 binding protein involving in $\mathrm{Ca}(2+)$ release from skeletal muscle sarcoplasmic reticulum. Mol Pharmacol 2000;57:1235-1242.

Smith RJ, Justen JM, McNab AR, Rosenbloom CL, Steele AN, Detmers PA, 49 Anderson DC, Manning AM: U-73122: a potent inhibitor of human polymorphonuclear neutrophil adhesion on biological surfaces and adhesionrelated effector functions. J Pharmacol Exp Ther 1996;278:320-329.
Malkowski MG, Ginell SL, Smith WL, Garavito RM: The productive conformation of arachidonic acid bound to prostaglandin synthase. Science 2000;289:1933-1937.

Meyer MC, Rastogi P, Beckett CS, McHowat J: Phospholipase A2 inhibitors as potential anti-inflammatory agents. Curr Pharm Des 2005;11:1301-1312.

Edwards DP: Regulation of signal transduction pathways by estrogen and progesterone. Annu Rev Physiol 2005;67:335-376.

Adcock IM,.Caramori G: Cross-talk between pro-inflammatory transcription factors and glucocorticoids. Immunol Cell Biol 2001;79:376-384.

Simonds WF: G protein regulation of adenylate cyclase. Trends Pharmacol Sci 1999;20:66-73.

Schmitt JM,.Stork PJ: beta 2-adrenergic receptor activates extracellular signalregulated kinases (ERKs) via the small $G$ protein rap 1 and the serine/threonine kinase B-Raf. J Biol Chem 2000;275:25342-25350.

Wess J, Blin N, Mutschler E, Bluml K: Muscarinic acetylcholine receptors: structural basis of ligand binding and $G$ protein coupling. Life Sci 1995;56:915922.

Hough LB: Genomics Meets Histamine Receptors: New Subtypes, New Receptors. Mol Pharmacol 2001;59:415-419.

Cazzola M,.Matera MG: 5-HT modifiers as a potential treatment of asthma. Trends Pharmacol Sci 2000;21:13-16. Yavarone MS, Shuey DL, Tamir H, Sadler TW, Lauder JM: Serotonin and cardiac morphogenesis in the mouse embryo. Teratology 1993;47:573-584.

Sarkar FH,.Li Y: Cell signaling pathways altered by natural chemopreventive agents. Mutation Research/Fundamental and Molecular Mechanisms of Mutagenesis. Mut Res 2004;555:53-64. Weber AA, Neuhaus T, Skach RA, Hescheler J, Ahn HY, Schror K, Ko Y, Sachinidis A: Mechanisms of the inhibitory effects of epigallocatechin-3 gallate on platelet-derived growth factorBB-induced cell signaling and mitogenesis. FASEB J 2004;18:128-130. Sauer H, Rahimi G, Hescheler J, Wartenberg M: Role of reactive oxygen species and phosphatidylinositol 3-kinase in cardiomyocyte differentiation of embryonic stem cells. FEBS Lett 2000;476:218-223.

Isbister GK,.Kiernan MC: Neurotoxic marine poisoning. Lancet Neurol 2005;4:219-228. 